\title{
Deconvolution and Curve Fitting of IR Spectra for CO Adsorbed on Pt/K-LTL: Potassium Promoter Effect and Adsorption Site Distribution
}

\author{
M. J. Kappers, ${ }^{\dagger}$ J. T. Miller, ${ }^{\ddagger}$ and D. C. Koningsberger $*, \dagger$ \\ Department of Inorganic Chemistry and Catalysis, Debye Institute, Utrecht University, P.O. Box 80083, 3508 \\ TB Utrecht, The Netherlands, and AMOCO Research Center, P.O. Box 3011, Naperville, Illinois 60566-7011
}

Received: August 28, $1995^{\otimes}$

Diffuse reflectance infrared (DRIFT) spectra have been obtained for carbon monoxide adsorbed with and without $\mathrm{H}_{2} \mathrm{O}$ on Pt/K-LTL zeolite. The complex spectra of $\mathrm{CO}$ linearly adsorbed on highly dispersed $\mathrm{Pt}$ have been analyzed by the combination of Fourier self-deconvolution and curve fitting. The linear-CO spectrum is composed of two broad multiplets: a high-frequency band (HFB) at $2100-1980 \mathrm{~cm}^{-1}$ and a low-frequency band (LFB) at $1990-1860 \mathrm{~cm}^{-1}$. The relative intensities of the HFB and LFB depend on the amount of coadsorbed water in the zeolite pores. The LFB is associated with an ion-dipole interaction between the oxygen atoms of $\mathrm{CO}$ species with potassium cations from the zeolite support. The HFB is associated with linear- $\mathrm{CO}$ unperturbed by the alkali promoter effect. It is proposed that water preferentially adsorbs on the $\mathrm{K}^{+}$ions, shielding the ion-dipole interaction. The individual components of the complex HFB and LFB are proposed to be due to $\mathrm{CO}$ molecules adsorbed on platinum atoms with different coordination numbers. The average coordination number of the Pt atoms in K-LTL, determined in the applied deconvolution and curvefitting program, corresponds well with that obtained by EXAFS, indicating a metal particle size distribution with particles containing between 1 and 13 platinum atoms. By applying the newly developed method, several literature IR CO spectra of Pt/K-LTL with different relative intensities in the HFB region have been analyzed successfully by adjusting the particle size distribution only. In view of the new results showing the prominent effects of particle size distribution and potassium promotion on the IR spectra of adsorbed CO, previously reported conclusions concerning metal-support interactions in PT/K-LTL should be reconsidered when based on infrared spectroscopic data.

\section{Introduction}

Early investigations have shown a considerably higher reforming selectivity of platinum supported on nonacidic LTLtype zeolites compared to the conventional alumina-based catalysts. ${ }^{1,2}$ Since then, numerous studies have been undertaken in order to better characterize and understand this catalyst. ${ }^{3-29}$ One technique used is infrared (IR) spectroscopy of adsorbed carbon monoxide. ${ }^{19-29}$ The stretching frequency of $\mathrm{CO}$ is very sensitive to the electronic structure of the metal surface onto which it is chemisorbed. ${ }^{30-48}$

The CO spectra obtained for the nonacidic Pt/LTL zeolites differ in two ways from those obtained for platinum supported on $\mathrm{SiO}_{2}, \mathrm{Al}_{2} \mathrm{O}_{3}$, and $\mathrm{H}^{+}$-exchanged zeolites. ${ }^{26,27}$ Instead of one linear-CO band in the region 2100-2040 $\mathrm{cm}^{-1}$, for Pt/LTL there are two absorption bands: one centered around $2060 \mathrm{~cm}^{-1}$ and one at $1960 \mathrm{~cm}^{-1} \cdot 21,23-26$ In some catalyst ${ }^{21,23-25}$ the lowfrequency band was only seen after heating to $225^{\circ} \mathrm{C}$, whereas Lane et al. ${ }^{26}$ observed both linear-CO bands instantly at room temperature. The low-frequency band (LFB) at $1960 \mathrm{~cm}^{-1}$ has been assigned to linearly bonded $\mathrm{CO}$, in which the oxygen atom of the molecule interacts with alkali cations in the zeolites pores. The discrepancy in the infrared results for Pt/LTL zeolites was resolved recently in our laboratory. ${ }^{25}$ It was shown that trace amounts of water absorb on the alkali cations and screen the ion-dipole interaction. In the presence of water, several highfrequency, linear-C $-\mathrm{O}$ bands are observed between 2060 and $1990 \mathrm{~cm}^{-1}$. In the absence of water, the $\mathrm{CO}$ bond is weakened

\footnotetext{
* To whom correspondence should be addressed.

$\dagger$ Debye Institute.

\$ AMOCO Research Center.

${ }^{\otimes}$ Abstract published in Advance ACS Abstracts, January 15, 1996.
}

by the $\mathrm{CO}$-alkali attraction, resulting in a band shift to lower frequency. The red shift was estimated to be more than 60 $\mathrm{cm}^{-1}$.

The CO spectra obtained for Pt/LTL differ in another aspect from those obtained for platinum on amorphous supports. The linear-CO band of Pt/LTL shows a series of distinct maxima between 2080 and $1980 \mathrm{~cm}^{-1},{ }^{21-29}$ whereas silica- and aluminasupported platinum show generally smooth $\mathrm{CO}$ spectra with a single maximum between 2100 and $2040 \mathrm{~cm}^{-1} .{ }^{27,30-41}$ So far, there has been little agreement on the origin of these high band components. It has been shown that the position of the complex high-frequency band (HFB) depends on the exchanged cation. ${ }^{21-24}$ It has been proposed therefore that the highly dispersed platinum particles are either geometrically influenced by the support to expose typical crystalline faces, edges, and corners ${ }^{21}$ or electronically changed by interaction with the zeolite. ${ }^{21-23}$ Recently, Sachtler and co-workers ${ }^{28,29}$ showed that the relative intensities of the linear-CO components depend on the preparation method of the catalyst. These authors suggested that the peaks represent discrete states of molecular adsorption onto several electronically different $\left(\mathrm{Pt}_{n} \mathrm{H}\right)^{+}$clusters. Another hypothesis proposes that the frequency of CO species absorbing in the $2100-2000^{-1}$ region depends on the degree of coordinative metal atom saturation. ${ }^{27,41-48}$ The series of overlapped peaks in the spectrum of Pt/K-LTL may therefore represent surface platinum atoms which vary in electron density due to their different coordination numbers. ${ }^{27}$

To understand the origin of the high-frequency $\mathrm{CO}$ band components and the effect of ion-dipole interactions induced by promoter ions, we have examined the infrared spectra of a $\mathrm{Pt} / \mathrm{K}-\mathrm{LTL}$ zeolite in the presence and absence of coadsorbed water in more detail. The prerequisite for a better analysis of 
the complex CO spectra is separation of the overlapped peaks by numerical techniques. An effective method of estimating the number and position of the band components is Fourier selfdeconvolution (FSD). ${ }^{49-59}$ The combination of deconvolution and curve fitting allows for qualitative as well as quantitative information on complex spectra. ${ }^{55-59}$ These recent developments in band analysis techniques have prompted this study of $\mathrm{CO}$ adsorbed on Pt/K-LTL. It will be shown that by combined FSD and curve fitting the linear-CO region of the IR spectrum of Pt/K-LTL consists of a larger number of highly overlapped components, which are grouped into a high- and low-frequency region due to the promotion effect of potassium cations. In addition, a comparison of the curve-fitted IR data of chemisorbed CO with EXAFS particle size determination indicates that the individual $\mathrm{CO}$ peaks represent different platinum adsorption sites, i.e., $\mathrm{CO}$ adsorbed on $\mathrm{Pt}$ atoms of different coordination number.

\section{Experimental Section}

Catalyst Preparation. Preparation of the zeolite catalyst is described elsewhere. ${ }^{10-26}$ In short, the K-LTL zeolite was obtained from Linde. Excess alkali was reduced by water wash until a $\mathrm{pH}$ of 9.5 to give a $\mathrm{K} / \mathrm{Al}$ ratio of 1.05 . The zeolite was impregnated with an aqueous solution of tetraamineplatinum(II) nitrate to give a sample containing $1.2 \mathrm{wt} \%$ platinum, followed by drying at $125^{\circ} \mathrm{C}$. Detailed structural characterizations of the catalyst by $\mathrm{H}_{2}$-TPD, hydrogen chemisorption, and EXAFS have been reported elsewhere. ${ }^{11-13}$ After reduction at $450{ }^{\circ} \mathrm{C}$ the platinum clusters contain ca. 10 atoms as estimated from the EXAFS first-shell platinum coordination number of $4.8 \pm$ $0.2 .^{12}$

Infrared Spectroscopy. The infrared measurements were performed in a diffuse reflectance accessory ("Collector", Barnes Analytic) equipped with a standard controlled environmental chamber (Spectra-Tech, Model 0030-103), connected to a flow system. ${ }^{25}$ It should be noted that $\mathrm{CO}$ gas $(4.7 \mathrm{~N})$ was stored in an aluminum cylinder and passed through copper tubing to prevent the formation of iron carbonyls. The catalyst sample was activated as neat powder as follows: (i) reduced in $10 \%$ $\mathrm{H}_{2} / \mathrm{Ar}$ at $5{ }^{\circ} \mathrm{C} / \mathrm{min}$ to $120{ }^{\circ} \mathrm{C}$ and kept at $120{ }^{\circ} \mathrm{C}$ for $0.5 \mathrm{~h}$, (ii) increased temperature to $450{ }^{\circ} \mathrm{C}$, reduced for $0.5 \mathrm{~h}$, and (iii) cooled to room temperature in a stationary atmosphere of $\mathrm{H}_{2} /$ Ar. No attempt was made to remove adsorbed hydrogen from the metal surface. A background spectrum was taken at room temperature in a stationary atmosphere of $\mathrm{H}_{2} / \mathrm{Ar}$ before switching to carbon monoxide.

In a previous IR study on the adsorption of $\mathrm{CO}$ on $\mathrm{Pt} / \mathrm{K}$ LTL, ${ }^{25}$ it was noted that the $\mathrm{CO}$ feed used was contaminated with water. In this study we have used this knowledge to obtain $\mathrm{CO}$ spectra with different concentration of coadsorbed water in the zeolite. Therefore, $\mathrm{CO}$ spectra were taken after 10 or $60 \mathrm{~s}$ of $\mathrm{CO}$ flow, followed by purging at room temperature with $\mathrm{Ar}$ in order to remove gaseous CO. The samples in these different stages of water contamination are designated as KL-med and KL-wet, respectively. To obtain a spectrum in the absence of water, designated as KL-dry, the sample was further heated in argon flow at $20{ }^{\circ} \mathrm{C} / \mathrm{min}$ to $200{ }^{\circ} \mathrm{C}$ and cooled to room temperature in a stationary atmosphere of argon. After heat treatment of sample KL-dry some of the CO is desorbed and therefore is not saturated anymore with adsorbate molecules. Because of the different surface coverages the relative intensities of the adsorption bands in the KL-wet and KL-dry sample cannot be compared.

The diffuse reflectance CO spectra were digitally corrected for the catalyst background spectrum and converted to Kubelka-
Munk $(\mathrm{K}-\mathrm{M})$ units. The intensity of bands in the $\mathrm{K}-\mathrm{M}$ spectrum should be proportional to the adsorbate concentration, and the band shapes should be equivalent to transmission spectra plotted linearly in absorbance. The spectra at $4 \mathrm{~cm}^{-1}$ resolution were recorded on a Perkin-Elmer 1720-X equipped with a DTGS detector (KL-wet) or a Perkin-Elmer System 2000 equipped with a liquid $\mathrm{N}_{2}$-cooled MCT detector (KL-med and KL-dry). The peak-to-peak noise of the spectra was about $0.7 \%$ and $0.01 \%$ reflectance for the respective systems.

Spectral Analysis. Curve-fitting methods yield the most information of complex spectra provided that the bands in the system conform to a few basic conditions. ${ }^{60,61}$ The number of bands and their positions can be accurately determined by fitting a highly deconvoluted spectrum, as was originally shown by Griffitsh et al. ${ }^{56,57}$ The procedure in the present study was as follows: (i) Fourier self-deconvolution of the experimental spectrum after base line correction, (ii) curve fitting of the (highly) deconvoluted spectrum, (iii) curve fitting of the original spectrum using the data set obtained from the previous step, (iv) check for similarity between the deconvoluted fitted and deconvoluted experimental spectrum using the same FSD parameters. $^{58,59}$

Curve fitting and Fourier self-deconvolution were performed with Advanced First software on a Mattson Instruments Data Station. Self-deconvolution is an interactive numerical method for time domain reduction of spectral bandwidth and resolution enhancement. The Mattson Instruments' deconvolution program DECON is based on the method described by Kauppinen et $a l .{ }^{49,51}$ The selected region of the spectrum is inverse Fourier transformed to yield a pseudointerferogram. The pseudointerferogram is then treated with a Bessel apodization function and enhancement factors $W$ and $K$ ( $W$ for the bandwidth at halfheight and $K$ for the enhancement parameter defined as the ratio of bandwidths of the enhanced and original band) to produce narrower band shapes. After this procedure the resulting interferogram is Fourier transformed back to the frequency domain. The fraction Lorentzian, $\alpha$, was used noninteractively to vary the band shape of the line shape function in the range from 1.0 (100\% Lorentzian) to 0.1 (10\% Lorentzian and $90 \%$ Gaussian). ${ }^{62}$

The curve-fitting program (Mattson Instruments' FIRST Curve-fit program) based on the damped least-squares optimization method developed by Levenberg ${ }^{63}$ and Marquardt ${ }^{64}$ allows all the band parameters, for example, intensity, frequency, halfbandwith, and band shape, to vary. The peak shape used in the curve-fitting routine was a linear combination of Lorentzian and Gaussian bands, with $\beta$ giving the Lorentzian fraction. The output of the calculations provides a value for the standard deviation, which is the square root of the sum of the squares of the residuals between the data and the best fit curve. For the calculations on the measured spectra the deviation was well below $10^{-4}$.

\section{Results}

The linear-CO spectra of Pt/K-LTL in different stages of $\mathrm{H}_{2} \mathrm{O}$ coadsorption are shown in Figure 1. The proposed coordination of water molecules with the $\mathrm{K}^{+}$ions in the zeolite pores has a dramatic effect on the $\mathrm{CO}$ spectrum. ${ }^{25}$ As the amount of water in the zeolite increases, the broad low-frequency band (LFB) between 2000 and $1860 \mathrm{~cm}^{-1}$ in the spectrum of KL-dry (Figure 1a) shifts to higher frequency with a more structured appearance. The high-frequency band (HFB) in the spectrum of KL-wet (Figure 1c) shows distinct maxima at 2049, 2031, and 2010 $\mathrm{cm}^{-1}$ and shoulders at 2065 and $1990 \mathrm{~cm}^{-1}$. The complex CO absorption band of KL-med (Figure 1b) contains the features 


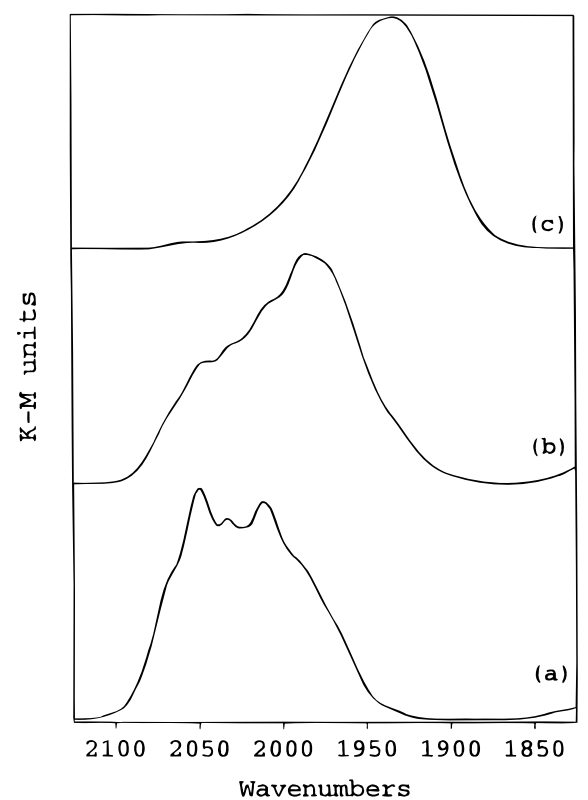

Figure 1. DRIFT spectra of carbon monoxide linearly adsorbed onto $\mathrm{Pt} / \mathrm{K}-\mathrm{LTL}$ zeolite at different stages of water coadsorption decreasing in the sequence (a) KL-wet, (b) KL-med, and (c) KL-dry.

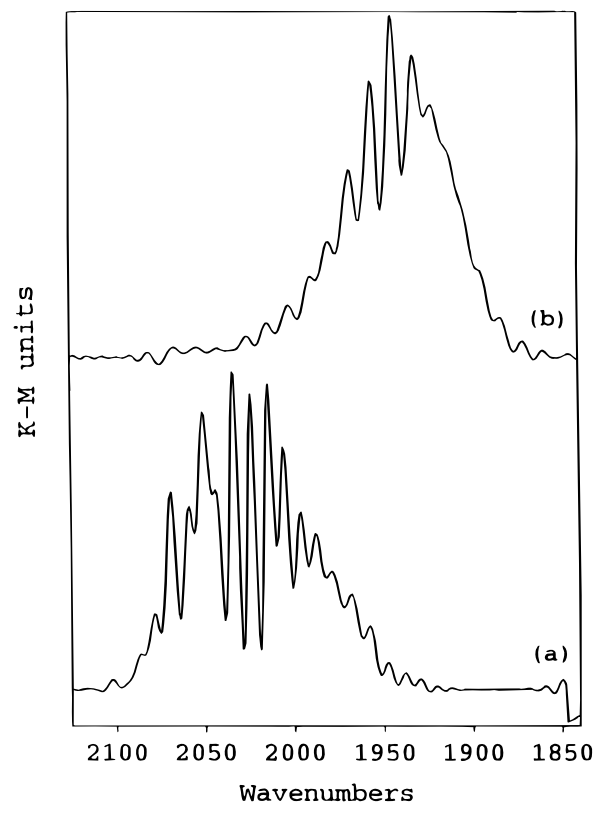

Figure 2. Fourier self-deconvolution of linear-CO spectra using a 14 $\mathrm{cm}^{-1}$ Gaussian function $(\alpha=0.1)$ and $K=2.0$ for KL-wet (a) and an $18 \mathrm{~cm}^{-1}$ Gaussian function $(\alpha=0.1)$ and $K=2.3$ for KL-dry (b).

of both KL-wet and KL-dry albeit with different intensities. A more detailed analysis on the effect of $\mathrm{H}_{2} \mathrm{O}$ on the linear-CO spectrum is now possible by deconvolving the spectra using the band analysis strategy as described in the Experimental Section.

Step $i$. The linear-CO bands in the spectra of Pt/K-LTL have been analyzed using Fourier self-deconvolution (FSD) after base line correction. The spectra shown in Figure 1 were analyzed using a Gaussian function $(\alpha=0.1)$ with individual peak widths in the range $10-20 \mathrm{~cm}^{-1}$. The value for the resolution enhancement factor $(K)$ was varied between 2.0 and 2.3, depending on the signal-to-noise ratio of the spectrum. For KLdry the maximum enhancement is achieved with $W=18 \mathrm{~cm}^{-1}$ (Figure 2a), whereas for KL-wet, excellent band separation is obtained with $W=14 \mathrm{~cm}^{-1}$ as can be observed in Figure $2 \mathrm{~b}$. This result indicates that the components absorbing between 2100 and $2000 \mathrm{~cm}^{-1}$ are narrower than those centered between

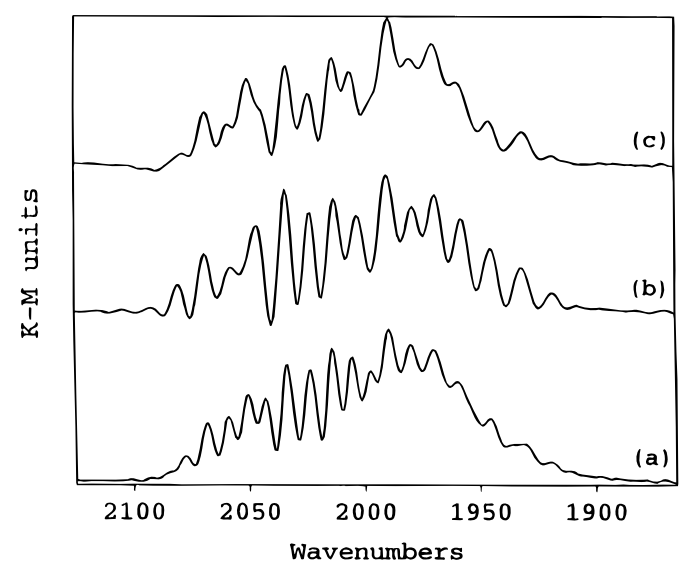

Figure 3. Fourier self-deconvolution of linear-CO spectra of KL-med using (a) a $14 \mathrm{~cm}^{-1}$ Gaussian function $(\alpha=0.1)$ and $K=2.3$; (b) an $18 \mathrm{~cm}^{-1}$ Gaussian function $(\alpha=0.1)$ and $K=2.3$; and (c) a $20 \mathrm{~cm}^{-1}$ Lorentzian function $(\alpha=1.0)$ and $K=3.2$.

2000 and $1850 \mathrm{~cm}^{-1}$. This is confirmed by deconvoluting the spectrum of KL-med, in which both types of components are present. The high-frequency peaks between 2100 and 2000 $\mathrm{cm}^{-1}$ are well-separated in KL-med with a bandwidth of 14 $\mathrm{cm}^{-1}$ (Figure 3a) but are overdeconvoluted with $W=18 \mathrm{~cm}^{-1}$, in which case the low-frequency components become much better resolved (Figure $3 \mathrm{~b}$ ). The effect of overdeconvolution using $W=18 \mathrm{~cm}^{-1}$ on the high-frequency components in the spectrum of KL-med in Figure $3 \mathrm{~b}$ results in the disappearance of features at 2042 and $1997 \mathrm{~cm}^{-1}$ as observed in Figure 3a (indicated with an arrow). Overdeconvolution, therefore, must be avoided when FSD is applied to determine the number of component bands and their position. The effect of overdeconvolution on the final results will be discussed in more detail below. Deconvolution using a predominantly Lorentzian line shape function yields comparable results as with a Gaussian function, however, with a lower resolution enhancement, as Figure $3 \mathrm{c}$ indicates. The overlapped components of the linear$\mathrm{CO}$ spectra are best described with Gaussians.

Step ii. Following FSD, the spectra are curve-fitted to obtain the number of components $(N)$ and their position $\left(v_{\mathrm{CO}}\right)$. The results of fitting the deconvolved spectra shown in Figure 2 and Figure $3 \mathrm{a}$ with purely Gaussian bands $(\beta=0.0)$ are illustrated in Figure 4. Also shown in the figures are the deconvoluted experimental spectra (i) and the differences between these and the sums of the component bands (ii). The deconvolved spectra can be fitted remarkably well. The widths of the resolved components in the $2100-1980 \mathrm{~cm}^{-1}$ region of the spectra (the HF region) are reduced to about $6-7 \mathrm{~cm}^{-1}$, whereas the bands in the $1990-1860 \mathrm{~cm}^{-1}$ region (the $\mathrm{LF}$ region) are slightly broader, i.e., $9-10 \mathrm{~cm}^{-1}$.

Step iii and iv. The base line-corrected experimental spectra have been fitted using the band frequencies determined in step ii. The intensity and bandwidth parameters were optimized while the frequency positions and band shape of the assumed Gaussian components $(\beta=0.0)$ were fixed during the calculations. The quality of the fits are very good as judged by the small standard deviation of the difference between the experimental and calculated spectra. The good fits with the purely Gaussian components, however, does not guarantee the correctness of the assumed band shape since the spectrum was fitted with a large number of bands. It is important to determine the form of the band shape accurately since it strongly affects the final intensities and bandwidths. In fitting the experimental spectrum of KL-med, the effect of increasing the Lorentzian fraction from 0 to $20 \%$ in the band shape $(\beta=0.0,0.1$, and 

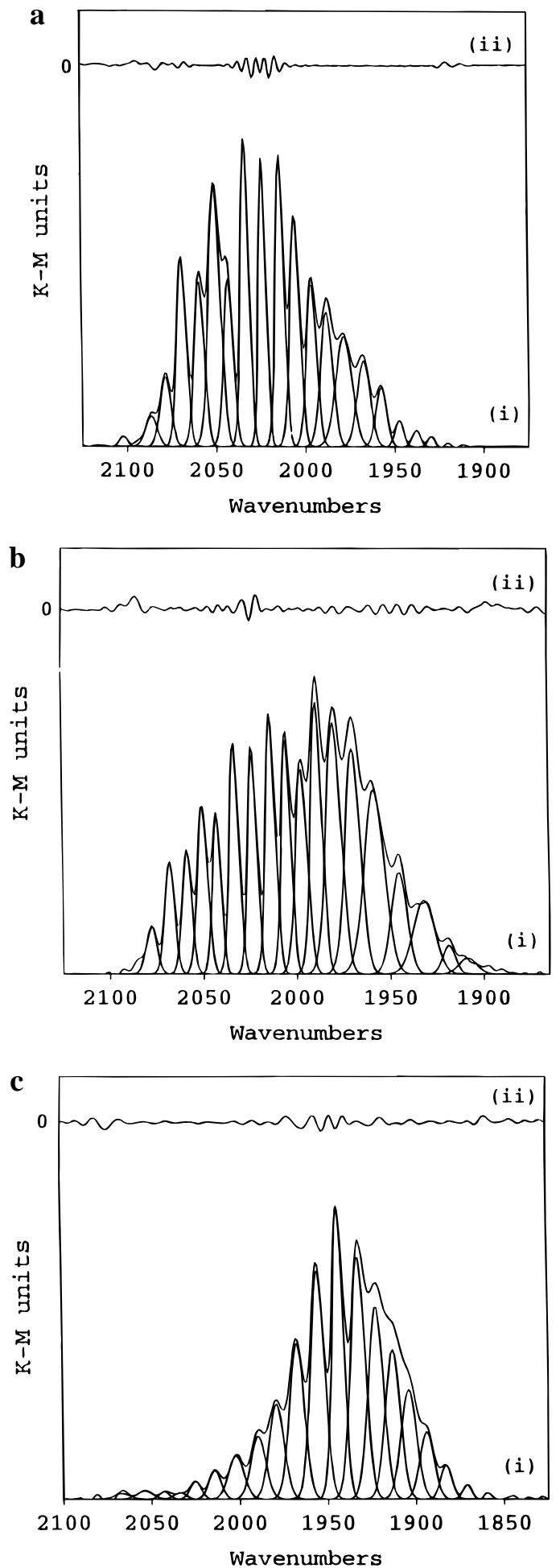

Figure 4. (a) Results of curve fitting the deconvolved linear-CO spectrum of KL-wet ( $W=14 \mathrm{~cm}^{-1}, K=2.0$, and $\alpha=0.1$ ) as shown in Figure 2a: (i) the deconvolved measured spectrum with the fitted component bands $(\beta=0.0)$; (ii) the difference between the deconvolved measured and fitted spectra. (b) Results of curve-fitting the deconvolved linear-CO spectrum of KL-med ( $W=14 \mathrm{~cm}^{-1}, K=2.3$, and $\alpha=0.1$ ) as shown in Figure 3a: (i) the deconvolved measured spectrum with the fitted component bands $(\beta=0.0)$; (ii) the difference between the deconvolved measured and fitted spectra. (c) Results of curvefitting the deconvolved linear-CO spectrum of KL-dry $\left(W=18 \mathrm{~cm}^{-1}\right.$, $K=2.3$, and $\alpha=0.1$ ) as shown in Figure 2b: (i) the deconvolved measured spectrum with the fitted component bands $(\beta=0.0)$; (ii) the difference between the deconvolved measured and fitted spectra.

0.2) only showed minor variations. However, the fit becomes rapidly worse with bands having more Lorentzian character than

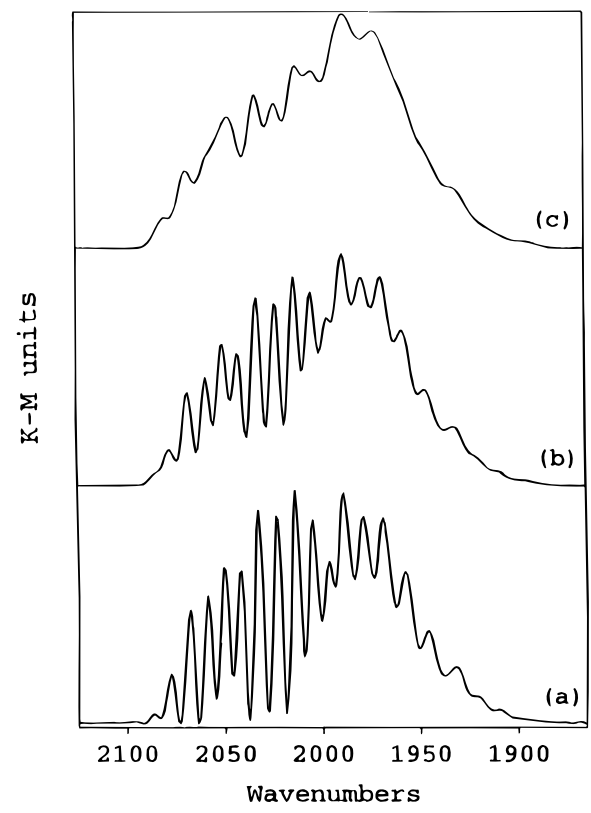

Figure 5. Fourier self-deconvolution of curve-fitted linear-CO spectra of KL-med ( $W=14 \mathrm{~cm}^{-1} K=2.3$, and $\alpha=0.1$ ) using (a) $100 \%$, (b) $90 \%$, and (c) $80 \%$ Gaussian-shaped band components ( $c f$. Figure 3a).

$20 \%(\beta>0.2)$. Although a good fit is obtained now for $0.0>$ $\beta>0.2$, still the band shape cannot be determined accurately, and therefore, the intensities and widths of the component bands in the fitting calculations remain inaccurate.

The final value of the band shape parameter $\beta$ can be determined by deconvoluting the calculated spectrum using the same FSD parameters as obtained for the experimental spectrum. ${ }^{58}$ In general, if a fitted spectrum correctly describes the experimental spectrum, deconvolution should yield similar results for both spectra. Consistency between the deconvolved spectra can then be made the essential criterion for accepting the curve-fitting parameters. To investigate the sensitivity for the band shape of the components, the experimental spectrum of KL-med is fitted using $\beta=0.0,0.1$, or 0.2 for the Gaussian bands and deconvoluted finally. The results are shown in Figure 5, with an increasing Lorentzian fraction from (a) to (c). It is clear from the figure that a small variation in band shape has a dramatic effect on the intensity of the resolved band components after FSD. The band shape parameter $\beta=0.1$ yields the smallest deviation in the difference between the deconvoluted experimental (viz. Figures $3 \mathrm{a}$ and $4 \mathrm{~b}$ ) and deconvoluted fitted spectrum in Figure 5b. Both the deconvoluted spectra are compared in Figure 6a. The agreement between the enhanced fitted and experimental spectra is equally good after FSD with Lorentzian functions as shown Figure 6b, instead of FSD with a Gaussian as in the example above. Thus, despite the comparable quality in fitting the experimental spectra using component bands with $\beta=0.0-0.2$ (not shown), the consistency between the deconvoluted experimental and deconvoluted calculated spectra indicates the correctness of the band shape with $\beta=0.1$ in the fitting calculations, irrespective of the FSD parameters used.

Apart from determination of the correct band shape of spectral components, step iv in the analysis is also used to determine whether the spectra are overdeconvoluted in step i. For example, the residual spectra of KL-med obtained by FSD with $W=18 \mathrm{~cm}^{-1}$ (viz. Figure $3 \mathrm{~b}$ ) is fitted in Figure 7. Note that there are fewer and broader components in the HF region of the spectrum using a width of $18 \mathrm{~cm}^{-1}$ than with $W=14 \mathrm{~cm}^{-1}$, indicating the spectral overdeconvolution. Although it is possible to fit the original spectrum of KL-med equally well 

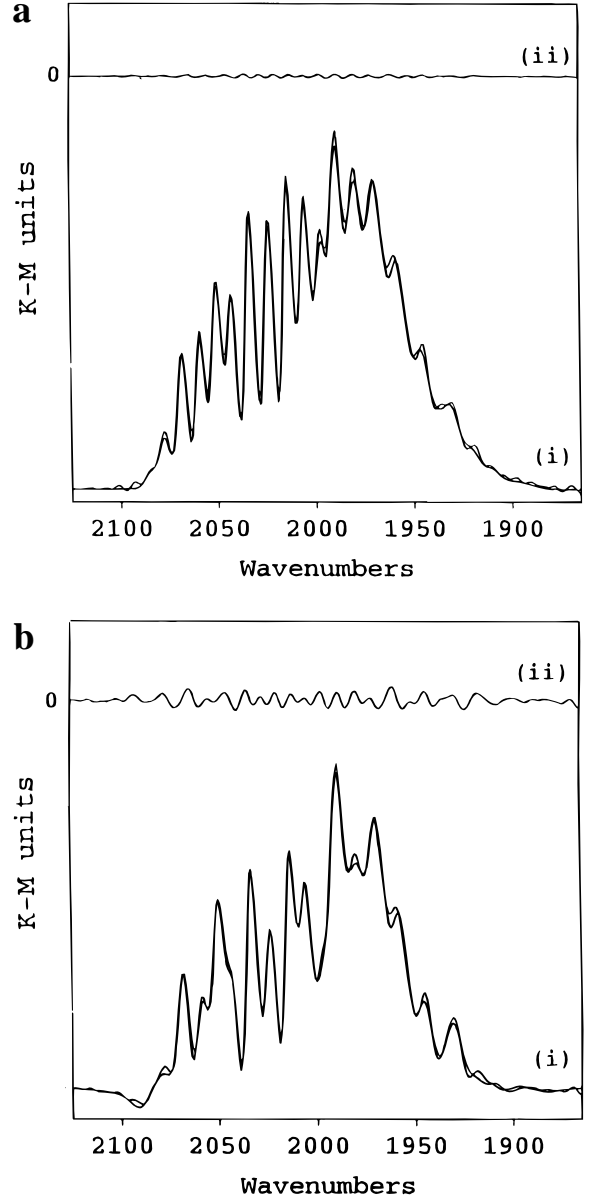

Figure 6. (a) Comparison between deconvolved measured and curvefitted linear-CO spectra of KL-med $\left(W=14 \mathrm{~cm}^{-1}, K=0.3\right.$, and $\alpha=$ 0.1 ): (i) the deconvolved measured and best-fit spectrum using $90 \%$ Gaussian-shaped band components ( $c f$. Figures $3 \mathrm{a}$ and $5 \mathrm{~b}$, respectively); (ii) the difference between the deconvolved measured and fitted spectra. (b) As in (a) with Fourier self-deconvolution using a $20 \mathrm{~cm}^{-1}$ Lorentzian function $(\alpha=1.0)$ and $K=3.2(c f$. Figure 3c).

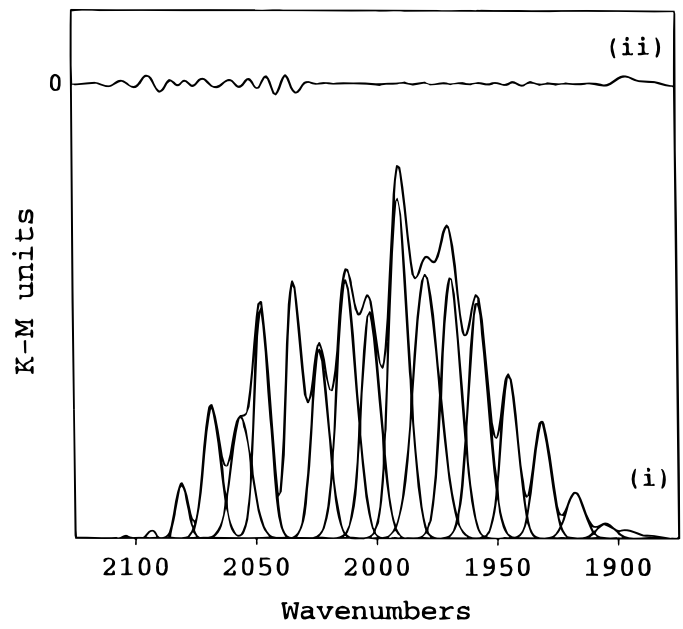

Figure 7. (a) Results of curve-fitting the deconvolved linear-CO spectrum of KL-med $\left(W=18 \mathrm{~cm}^{-1}, K=2.0\right.$, and $\left.\alpha=0.1\right)$ : (i) the deconvolved measured spectrum with the fitted component bands $(\beta$ $=0.0$ ); (ii) the difference between the deconvolved measured and fitted spectra.

with the number of peaks and their positions determined in Figure 7, the number of band components is too small. The detection of this misinterpretation in the number of bands is illustrated in Figure 8. Both the experimental and computed spectra are subsequently deconvoluted using $W=18$ and 14
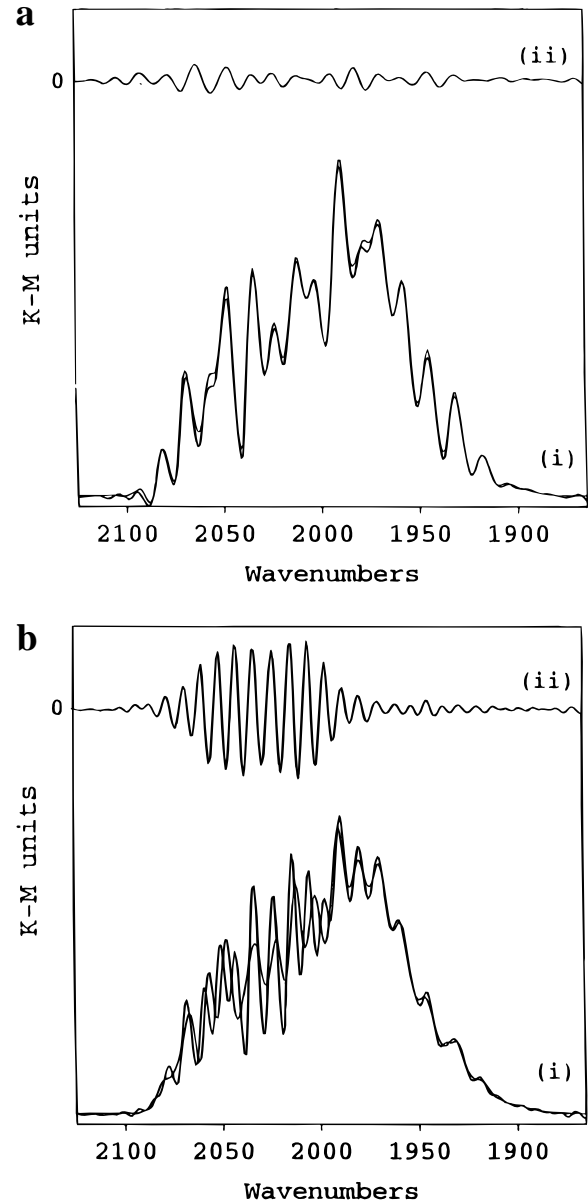

Figure 8. (a) Comparison between deconvolved measured and curvefitted linear-CO spectra of KL-med $\left(W=18 \mathrm{~cm}^{-1}, K=2.0\right.$, and $\alpha=$ 0.1 ): (i) the deconvolved measured and best-fit spectrum using $90 \%$ Gaussian-shaped band components as determined in Figure 7a; (ii) the difference between the deconvolved measured and fitted spectra. (b) As in (a) with Fourier self-deconvolution using $W=14 \mathrm{~cm}^{-1}, K=$ 2.3 , and $\alpha=0.1$.

$\mathrm{cm}^{-1}$, as shown in Figure 8 , and $\mathrm{b}$, respectively. While the difference between the deconvolved spectra obtained using a width of $18 \mathrm{~cm}^{-1}$ is quite good (Figure $8 \mathrm{a}-\mathrm{ii}$ ), a very poor fit is obtained in the $\mathrm{HF}$ region using $W=14 \mathrm{~cm}^{-1}$ for deconvolution of both spectra as indicated by the difference curve in Figure $8 b-$ ii. This illustrates the superiority of the parameters obtained from the highly deconvoluted spectrum in Figure $3 \mathrm{a}$ or $4 \mathrm{~b}$. In conclusion, step iv of the analysis procedure appears a reliable action to prevent errors in determining the correct band parameters, in the amount of band components and their position as well as their shape.

The final results using Gaussian bands with $\beta=0.1$ for curve fitting the experimental linear-CO spectra of Pt/K-LTL are shown in Figure 9. The positions and widths of the $\mathrm{CO}$ components are listed in Table 1. The parameters from the wellresolved peaks in the deconvoluted spectra are more reliable than those of the less-resolved peaks. To illustrate this, the former data are printed in bold. Comparison of the curve fitting results shows that the (more reliable) peak positions only deviate $2 \mathrm{~cm}^{-1}$ in the three spectra. We thus located the frequency positions for the different linear-CO species adsorbed on $\mathrm{Pt} / \mathrm{K}$ LTL, covering the region between 2100 and $1860 \mathrm{~cm}^{-1}$. The average width of the component bands in the HF region varies between 13 and $15 \mathrm{~cm}^{-1}$ whereas the bandwidths in the LF region are between 19 and $23 \mathrm{~cm}^{-1}$. 

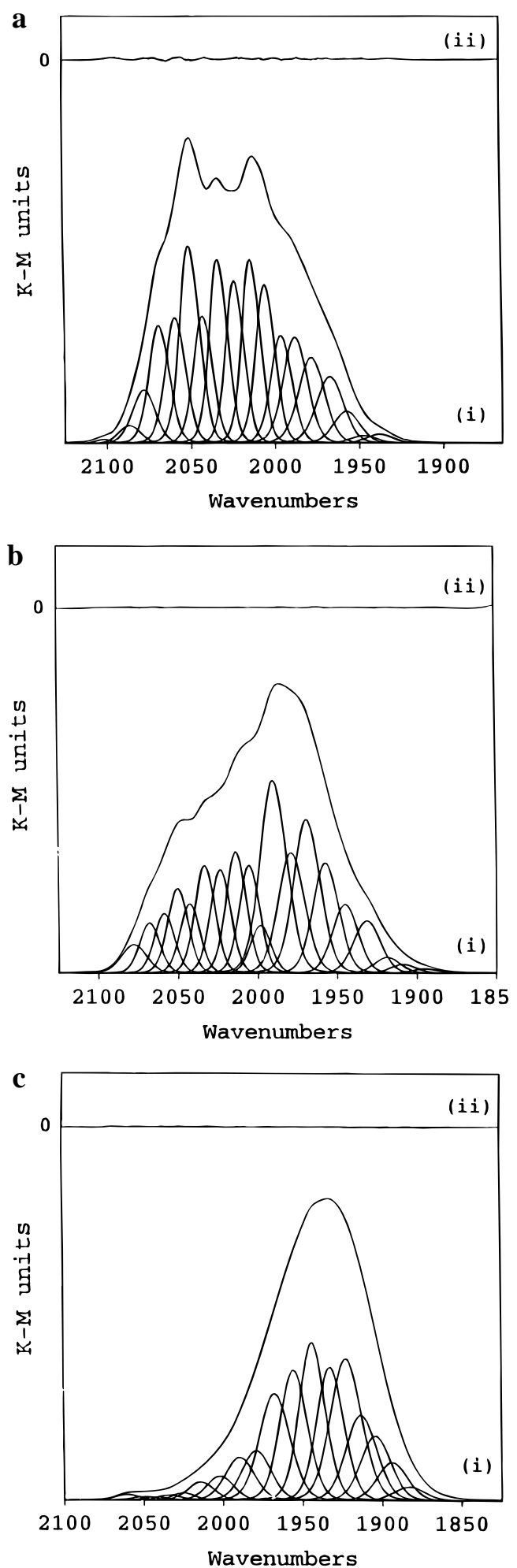

Figure 9. (a) Results of curve fitting the measured linear-CO spectrum of KL-wet as shown in Figure 1a: (i) the measured spectrum with the fitted component bands $(\beta=0.1)$; (ii) the difference between the measured and fitted spectra. (b) Results of curve fitting the measured linear-CO spectrum of KL-med as shown in Figure 1b: (i) the measured spectrum with the fitted component bands $(\beta=0.1)$; (ii) the difference between the measured and fitted spectra. (c) Results of curve fitting the measured linear-CO spectrum of KL-dry as shown in Figure 1c: (i) the measured spectrum with the fitted component bands $(\beta=0.1)$; (ii) the difference between the measured and fitted spectra.

\section{Discussion}

Band Analysis Routine. The combined use of Fourier selfdeconvolution and curve fitting indicates the presence of at least
24 intrinsically overlapped peaks in the linear- $\mathrm{CO}$ region of $\mathrm{Pt} /$ K-LTL. The position of the most intense peaks is determined within $2 \mathrm{~cm}^{-1}$ by curve fitting the highly deconvoluted spectra, as can be observed in Table 1. The number of peaks and their positions as determined in step $i$ and step ii of the analysis strategy have been used as fixed input parameters in the curvefitting calculations of the experimental spectra in step iii. A powerful check for the accuracy of the calculated band parameters is performed with step iv, i.e., comparison between the deconvoluted experimental and deconvoluted calculated spectra using the same parameters, as was originally shown by Friesen and Michaelian. ${ }^{58,59}$ Small adjustments to the band parameters can then be made to optimize the fit. The difference spectra obtained in step iv clearly show when band components are real or absent, e.g., due to overdeconvolution in step i.

Linear-CO Band Assignment. Potassium Promoter Effect. The results from spectral analysis indicate the presence of two partly overlapping multiplets located in the regions 2100-1980 and $1990-1860 \mathrm{~cm}^{-1}$ of the linear-CO spectrum of Pt/K-LTL. For the spectrum of KL-wet (Figure 1c), the high-frequency band (HFB) components are more intense than those of the lowfrequency band (LFB). By contrast, the HFB in KL-dry is nearly absent. The relative intensities of the HFB and LFB depend on the water content of the zeolite. These results are consistent with the ion-dipole model, in which the $\mathrm{CO}$ band shift in the spectra of Pt/K-LTL is the result of electrostatic interaction between $\mathrm{K}^{+}$ions and the dipole of the adsorbed $\mathrm{CO}$ molecule. ${ }^{25,26}$ Water molecules present in the "wet" samples inhibit the ion-dipole formation by coordination with the cations. Hence, the overlapped component bands of the HFB are assigned to unperturbed $\mathrm{CO}$ species whereas those of the LFB are due to adsorbed $\mathrm{CO}$ purturbed by the polarization from potassium cations. A schematic representation of the linearCO region of Pt/K-LTL is shown in Figure 10.

The screening of the ion-dipole interaction by adsorbed $\mathrm{H}_{2} \mathrm{O}$ requires that the $\mathrm{K}^{+}$ions must be nearby the platinum clusters. The interacting alkali are likely charge-balancing cations located at specific sites in the zeolite walls ${ }^{65}$ but may also include the ca. $5 \%$ excess alkali over the ion-exchange capacity.

Considering the relative positions of the HFB and the LFB, the magnitude of the red shift due to ion-dipole complex formation is estimated at $100 \mathrm{~cm}^{-1}$. Slightly larger frequency shifts (viz. 110-160 $\mathrm{cm}^{-1}$ ) have been observed for bridgebonded $\mathrm{CO}$ on supported $\mathrm{Rh}$ promoted with oxophillic cations $\mathrm{Ti}, \mathrm{V}, \mathrm{Mn}, \mathrm{Zr}$, and $\mathrm{Nb}^{66}$ and for alkali-promoted $\mathrm{Pd} / \mathrm{SiO}_{2}$ and $\mathrm{Rh} / \mathrm{SiO}_{2}$ catalysts. ${ }^{67,68}$ These frequency shifts were interpreted in terms of direct interactions between the promoter ions, e.g., highly charged transitions metal cations, and the oxygen atom of (possibly tilted) bridging CO. The magnitude of the red shift has been calculated by Holloway et al. to be between 50 and $200 \mathrm{~cm}^{-1}$, depending on factors as geometry and surface coverage. ${ }^{69}$

The calculated bandwidths between 13 and $15 \mathrm{~cm}^{-1}$ for the linearly bonded molecules making up the HFB are slightly larger than the $12 \mathrm{~cm}^{-1}$ observed for similar species on single-crystal surfaces. ${ }^{70}$ Further, the absortion bands observed for the wellordered systems on single-crystal surfaces have an approximate Lorentzian shape, whereas analysis of spectra for the Pt/K-LTL supported catalyst indicates that the bands are for $90 \%$ Gaussianshaped. It appears that the broader, Gaussian-shaped peaks in the spectra of Pt/K-LTL are inherent to $\mathrm{CO}$ adsorbed on supported metal particles, possibly due to the inhomogeneous distribution of individual $\mathrm{CO}$ frequencies or intermolecular interactions. ${ }^{71,72}$ In addition, it appears that the electrostatic attraction between adsorbed $\mathrm{CO}$ molecules and the alkali cations 
TABLE 1: Curve-Fit Results of IR Spectra of Linear-CO on Pt/K-LTL

\begin{tabular}{|c|c|c|c|c|c|c|c|}
\hline \multicolumn{2}{|c|}{ KL-dry } & \multicolumn{2}{|c|}{ KL-med } & \multicolumn{2}{|c|}{ KL-wet } & \multirow{2}{*}{$\begin{array}{l}\text { proposed band } \\
\text { assignment }\end{array}$} & \\
\hline$\nu_{\mathrm{CO}}\left(\mathrm{cm}^{-1}\right)$ & $\mathrm{HBW}\left(\mathrm{cm}^{-1}\right)$ & $v_{\mathrm{CO}}\left(\mathrm{cm}^{-1}\right)$ & $\operatorname{HBW}\left(\mathrm{cm}^{-1}\right)$ & $\nu_{\mathrm{CO}}\left(\mathrm{cm}^{-1}\right)$ & $\operatorname{HBW}\left(\mathrm{cm}^{-1}\right)$ & & \\
\hline & & & & 2102 & 11 & electron-efficient $\mathrm{Pt}$ (ref 22) & \\
\hline & & & & 2087 & 15 & 10-coordinated & \multirow{11}{*}{$\begin{array}{l}\mathrm{HFB} \text { components: } \\
\text { unperturbed } \mathrm{CO} \text { species }\end{array}$} \\
\hline & & 2078 & 18 & 2079 & 16 & 9-coordinated & \\
\hline 2067 & 17 & 2068 & 15 & 2069 & 14 & 8-coordinated & \\
\hline 2054 & 16 & 2059 & 15 & 2060 & 14 & 7-coordinated & \\
\hline & 16 & 2050 & 15 & 2051 & 14 & 6-coordinated & \\
\hline 2043 & 16 & 2043 & 15 & 2043 & 14 & 5-coordinated & \\
\hline 2034 & 16 & 2033 & 15 & 2034 & 13 & 4-coordinated & \\
\hline 2025 & 16 & 2024 & 15 & 2024 & 13 & 3-coordinated & \\
\hline 2014 & 19 & 2014 & 15 & 2014 & 13 & 2-coordinated & \\
\hline \multirow[t]{2}{*}{2002} & 20 & 2005 & 15 & 2006 & 13 & 1-coordinated & \\
\hline & & 1997 & 15 & 1997 & 15 & 0 -coordinated & \\
\hline 1990 & 21 & 1990 & 20 & 1988 & 17 & 10-coordinated & \multirow{12}{*}{$\begin{array}{l}\text { HFB components: } \\
\text { perturbed } \mathrm{CO} \text { species }\end{array}$} \\
\hline 1979 & 21 & 1979 & 20 & 1979 & 18 & 9-coordinated & \\
\hline 1968 & 22 & 1969 & 20 & 1968 & 19 & 8 -coordinated & \\
\hline 1956 & 20 & 1957 & 19 & 1958 & 18 & 7-coordinated & \\
\hline 1944 & 19 & 1945 & 19 & 1948 & 18 & 6-coordinated & \\
\hline 1933 & 20 & 1931 & 20 & 1938 & 18 & 5-coordinated & \\
\hline 1923 & 23 & 1919 & 19 & & & 4-coordinated & \\
\hline 1913 & 23 & 1909 & 19 & & & 3-coordinated & \\
\hline 1904 & 22 & 1895 & 19 & & & 2-coordinated & \\
\hline 1894 & 22 & & & & & 1-coordinated & \\
\hline 1883 & 23 & & & & & 0 -coordinated & \\
\hline 1871 & 24 & & & & & unknown & \\
\hline
\end{tabular}

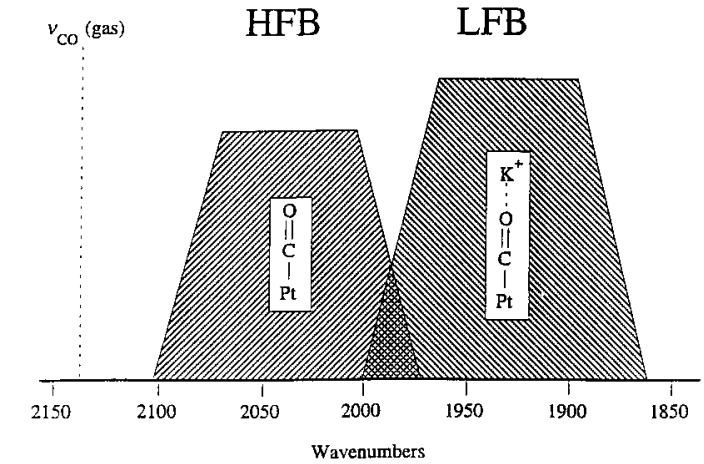

Figure 10. Schematic representation of the linear-CO spectrum from adsorption on Pt/K-LTL zeolite showing the high-frequency band (HFB) and low-frequency band (LFB) relative to the gasphase value of $v_{\mathrm{CO}}$ $=2143 \mathrm{~cm}^{-1}$.

in the zeolite pores increases the bandwidth as well; $c f$. Table 1. Similarly, the increased bandwidth of the LFB components with respect to the HFB components may be caused by inhomogeneous broadening arising from an inhomogeneous distribution of the individual $\mathrm{CO}$ oscillator frequencies determined by the ion-dipole interaction.

Metal Adsorption Site Distribution. The results of the FSD analysis yields band positions for a large number of overlapping peaks for both the HFB and LFB in the linear-CO spectra of $\mathrm{Pt} / \mathrm{K}-\mathrm{LTL}$. It should be noted that the spectra are obtained under $\mathrm{CO}$ saturation and thus include effects of vibrational coupling and chemical shifts. However, since the metal clusters are very small, chemical and physical contributions to the coverage induced frequency shift are likely to be small. Some of the bands listed in Table 1 have been observed before. For example, Sachtler and colleagues ${ }^{28,29}$ observed (without the use of resolution enhancement) maxima at 2105, 2066, 2051, 2031, 2008, 1998, and $1919 \mathrm{~cm}^{-1}$ for CO adsorbed on several Pt/KLTL samples obtained under similar conditions as the KL-wet sample in the present study. These authors showed that the relative intensities of the linear- $\mathrm{CO}$ peaks depend on the preparation method of the catalyst, i.e., ion-exchange (IE), incipient wetness impregnation (IWI), and coimpregnation with $\mathrm{KCl}(\mathrm{IWI}+\mathrm{KCl})$. It was speculated that these peak maxima represent $\mathrm{CO}$ molecules bonded to metal-proton adducts (e.g., $\left(\mathrm{Pt}_{n} \mathrm{H}\right)^{+}$clusters) with a different degree of electron deficiency. ${ }^{28,29}$ Alternatively, we suggest that the multiple peak intensities in the infrared spectra of Pt/K-LTL are due to the relative amount of $\mathrm{CO}$ on platinum atoms with a different number of platinum neighbors. Model calculations by Van Hardeveld and Hartog ${ }^{42}$ have shown that type and number of the exposed single-atom sites depend largely on the particle size. Large crystallites expose mainly high coordinated atoms, e.g., $\mathrm{CN}=8-10$, whereas the surface of small clusters consists of highly unsaturated sites, for example $\mathrm{CN}=5$ or lower. The frequency of carbon monoxide molecules adsorbed onto group VIII metal particles has been shown to be influenced by the coordination number of the metal adsorption site involved..$^{27,41-48}$ The linearly bonded $\mathrm{CO}$ frequency decreases with a decreasing number of neighboring metal atoms, i.e., with an increasing degree of coordinative unsaturation. Theoretical and experimental results ${ }^{73-78}$ indicate that coordinatively unsaturated metal sites have a higher $d$ valence electron band filling at the Fermi level due to the narrowing of the local density of states (LDOS) and a center-of-gravity shift to lower binding energy. The narrowed LDOS concentrated near the Fermi level leads to increased overlap with the $2 \pi^{*}$ MO's of adsorbed CO. The increase in electron density with increasing degree of coordinative unsaturation leads to a higher occupation (back-donation) of the $2 \pi^{*}$ orbitals, resulting in a weakening of the $\mathrm{C}-\mathrm{O}$ bond and a red shift of the $v_{\mathrm{CO}}$ frequency. ${ }^{79}$

The above interpretation suggests that the various infrared peaks between 2100 and $1980 \mathrm{~cm}^{-1}$ represent unperturbed adsorbate molecules bonded to surface platinum atoms with different number of metal neighbors, with a frequency difference of about $9-10 \mathrm{~cm}^{-1}$ in agreement with earlier reports. ${ }^{27,47}$ If this is true, the clusters enclosed in the zeolite channels would expose platinum surface atoms with a range of coordination numbers between 0 and 10. A first-shell $\mathrm{Pt}-\mathrm{Pt}$ coordination number of 4.8 has been obtained with EXAFS. ${ }^{12,13}$ EXAFS can not discriminate between the presence of particles with a uniform size or with a size distribution. However, from the EXAFS results one can conclude that the platinum clusters in $\mathrm{Pt} / \mathrm{K}$-LTL indeed contain about 10 atoms on average with an upper limit of about 13 atoms because of the lack of high 
TABLE 2: Calculation of Average Pt Coordination in Pt/K-LTL from the Linear-CO Spectrum of KL-wet (See Text) ${ }^{a}$

\begin{tabular}{ccccc}
\hline \multirow{2}{*}{$\begin{array}{c}\text { Pt coordination } \\
\text { number } \mathrm{C}_{n}\end{array}$} & \multicolumn{3}{c}{ calculated band areas $A(\mathrm{au})$} & \\
\cline { 2 - 4 } & $\mathrm{HFB}$ & $\mathrm{LFB}^{b}$ & $\mathrm{HFB}+\mathrm{LFB}$ & $\mathrm{C}_{n} A_{\text {total }}$ \\
\hline 10 & 0.035 & 0.069 & 0.104 & 1.041 \\
9 & 0.113 & 0.060 & 0.173 & 1.560 \\
8 & 0.221 & 0.049 & 0.270 & 2.159 \\
7 & 0.235 & 0.022 & 0.257 & 1.801 \\
6 & 0.361 & 0.005 & 0.366 & 2.196 \\
5 & 0.226 & 0.006 & 0.232 & 1.161 \\
4 & 0.312 & 0.000 & 0.312 & 1.248 \\
3 & 0.276 & 0.000 & 0.276 & 0.828 \\
2 & 0.312 & 0.000 & 0.312 & 0.624 \\
1 & 0.278 & 0.000 & 0.278 & 0.278 \\
0 & 0.208 & 0.000 & 0.208 & 0.000 \\
& & & $2.789^{c}$ & $12.896^{c}$
\end{tabular}

${ }^{a}$ Average surface Pt coordination number $=\sum\left(\mathrm{C}_{n} A_{\text {total }}\right) / \sum\left(A_{\text {total }}\right)=$ $12.9 / 2.8=4.6 .{ }^{b}$ Band areas of LFB components are corrected for assumed higher absorptivity (factor 3.4).$^{24 c}$ Total.

coordination shell contributions. ${ }^{12}$ Therefore, the EXAFS results do not disagree with the above-mentioned particle size distribution. The proposed band assignments together with the calculated linear-CO peak parameters for Pt/K-LTL in different stages of water contamination are listed in Table 1.

The combination of deconvolution and curve-fitting forms the basis for obtaining structural information from the linearCO spectrum of Pt/K-LTL. As the IR band areas relate to the concentration of the various surface $\mathrm{Pt}$ atoms, the average metal coordination number may be estimated from the relative intensities of the linear-CO components. In Table 2 the band areas of the KL-wet spectrum have been listed with the proposed assignments. For calculating the specific substrate concentration it is assumed that the molecular absorption coefficient of the HFB species is independent of the Pt coordination number. Further, the absorptivities of the LFB species are greater than those of the HFB species. Han et al. ${ }^{24}$ recently estimated that the absorptivities of the species present after heating (i.e., the LFB species) are a factor of 3.4 stronger than those of the CO species present at room temperature (the HFB species). From the curve fitting of KL-wet an average coordination number of platinum surface atoms is thus calculated at 4.6 compared to an average first shell Pt coordination number of $4.8 \pm 0.2$ by EXAFS. The agreement between the average particle size obtained by EXAFS and the results of the FSD and curve-fitting analysis methods is a strong indication of the presence of a platinum particle size distribution.

This particle size distribution with an average cluster size containing 10 atoms suggests that the platinum clusters were of an average size of about $6 \AA$ and few larger than $9 \AA$. Moreover, from the data in Table 2 it can be easily calculated that nearly $40 \%$ of the total CO band intensity in the sample $\mathrm{KL}$-wet is due to adsorbates on $\mathrm{Pt}$ atoms with coordination numbers $\mathrm{CN}<4$, i.e., on metal clusters containing fewer than 5 atoms. Thus, a considerable part of the Pt clusters in the LTL channels is smaller than $5 \AA$ in diameter. Considering the detection limit of the STEM technique, our data do not contradict with the results reported by McVicker et al. ${ }^{16}$ for their Pt/LTL zeolite catalyst. It seems, however, that the clusters in the catalyst studied by McVicker are slightly larger, due to a different preparation method. The observation that very small platinum clusters $(<10 \AA)$ exist in the channel of the LTL zeolite is not new. For instance, Vaarkamp et al. ${ }^{15}$ studied the effect of sulfur on a Pt/BaK-LTL zeolite catalyst which had a $\mathrm{Pt}-\mathrm{Pt}$ coordination number of 3.7 and an $\mathrm{H} / \mathrm{Pt}$ ratio of 1.4 , consistent with Pt clusters containing 5-6 atoms on average. Additionally,
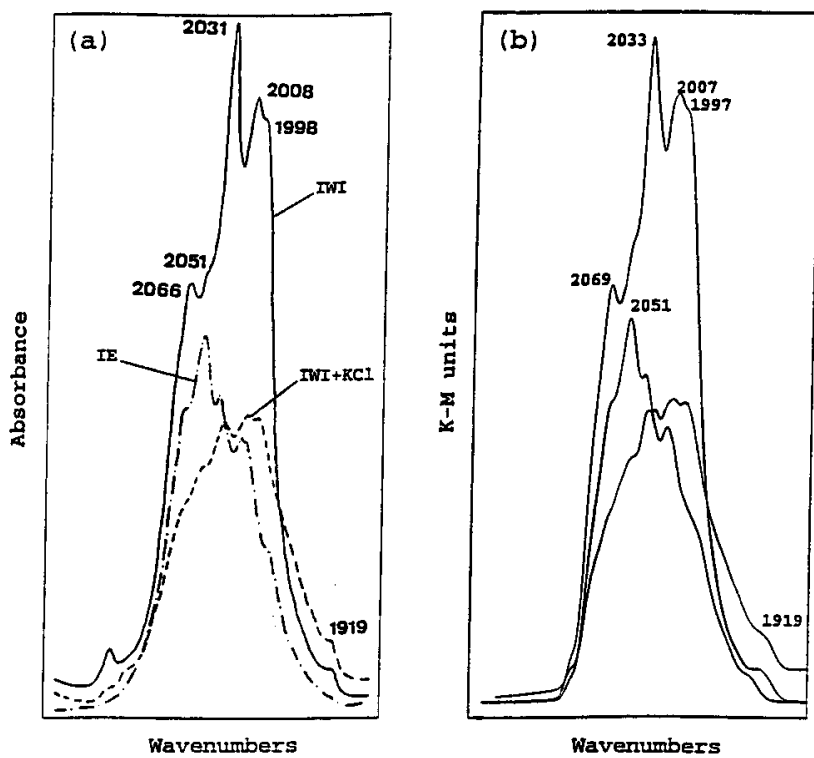

Figure 11. (a) Transmission FT-IR spectra of $\mathrm{CO}$ adsorbed onto Pt/ KL-IE, Pt/KL-IW, and Pt/KL-IW+KCl zeolite as reported by Kustov et al. ${ }^{26}$ (b) Simulated CO spectra using band parameters of KL-wet as summarized in Table 1.

according to a $\mathrm{H} / \mathrm{Pt}$ ratio of 1.56 the LTL zeolite supported $\mathrm{Pt}$ clusters as studied by Mielczarski et al. ${ }^{20}$ must have been even smaller. The ability of the LTL zeolite to stabilize such very small metal clusters may be the result of the unidimensional pore structure combined with a very small pore size.

The proposed interpretation for $\mathrm{CO}$ spectra suggests that the infrared spectra of Pt/K-LTL catalysts is determined by the platinum particle size distribution, where the spectrum is composed of the same type of $\mathrm{CO}$ peaks, but varying in relative intensity only. To test this model, the linear-CO spectra from other Pt/K-LTL catalysts reported in the literature have been simulated. To obtain a fit, the peak frequencies in the spectrum of our KL-wet catalyst, listed in Table 1, were used, and only the band intensities were varied in order to calculate the IR spectra from the Pt/KL-IE (ion-exchange), Pt/KL-IWI (incipient wetness impregnation), and $\mathrm{Pt} / \mathrm{KL}-\mathrm{IWI}+\mathrm{KCl}$ reported by Kustov et $a l .{ }^{28}$ (Figure 11a). The IR spectra of Kustov et al. were simulated by assuming that the individual bands represent $\mathrm{CO}$ adsorbed on $\mathrm{Pt}$ atoms of different coordination and that the differences among the spectra is related to the distribution of coordination environments. Furthermore, the calculated $\mathrm{Pt}$ coordination numbers from the FSD analysis are 5.2, 4.7, and 4.6 for IE, IWI + KCL, and IWI, respectively, and is consistent with the observation that a catalyst prepared by impregnation contains smaller metal clusters than one prepared by ion exchange. . $11,13,28,29$ Since the spectra can be accurately simulated by adjusting the particle size distribution (Figure 11b), we conclude that the differences in the CO IR spectra are caused predominantly by the differences in platinum particle size distribution, rather than by the formation of metal-proton adducts. $^{28}$

Finally, in the literature CO/IR band shifts have been interpreted to be caused by differences in electronic properties of platinum induced by interaction with the LTL support exchanged with different alkali cations. ${ }^{21-24}$ The results described in this and previous studies ${ }^{25,26}$ demand for a reinterpretation of the linear- $\mathrm{CO}$ spectrum for the different catalysts. In addition to possible contributions from metalsupport interactions, the CO spectrum is largely influenced by ion-dipole interactions and metal particle size distribution. The occurrence of intense infrared absorbances in the 2000-1900 
$\mathrm{cm}^{-1}$ region in the spectrum of adsorbed $\mathrm{CO}$ on nonacidic catalysts is not due to metal particles interacting with the support but must be attributed to the electrostatic $\mathrm{CO}$-alkali interaction. By curve fitting the $\mathrm{CO}$ spectra measured in the presence of coadsorbed water in the catalyst (thereby screening the alkali promotion effect), the influence of different particle size distributions can be separated from a possible support effect. Only then it is possible to compare $\mathrm{CO}$ (singleton) frequencies from platinum coordination sites of metal particles supported on different types of catalysts with the corresponding frequencies from electronically neutral, single crystals. ${ }^{46-48,70}$

\section{Conclusions}

Fourier self-deconvolution in combination with curve fitting have been applied successfully to the analysis of infrared spectra of $\mathrm{CO}$ adsorbed on a $\mathrm{Pt} / \mathrm{K} / \mathrm{LTL}$ catalyst. The spectrum of linearly adsorbed $\mathrm{CO}$ consists of two broad multiplets. The high-frequency band (HFB) between 2100 and $1980 \mathrm{~cm}^{-1}$ is due to the unperturbed $\mathrm{CO}$ species adsorbed onto the highly dispersed platinum clusters. An ion-dipole interaction between the oxygen atoms of adsorbed $\mathrm{CO}$ and $\mathrm{K}^{+}$ions from the support results in a red shift of the absorption frequency of about 100 $\mathrm{cm}^{-1}$, giving rise to the second, low-frequency band (LFB). The $\mathrm{CO}-$ alkali ion-dipole attraction is screened by adsorption of water on the $\mathrm{K}^{+}$ions. Fourier self-deconvolution of the linearCo multiplets indicates that the HFB and LFB are composed of a large number of intrinsically overlapped peaks. The individual bands calculated from the $\mathrm{CO}$ spectrum of Pt/K-LTL are assigned to platinum atoms with different platinum coordination numbers. The average platinum coordination obtained from the analysis of the individual $\mathrm{CO}$ bands agrees with the average first-shell $\mathrm{Pt}-\mathrm{Pt}$ coordination number as determined by EXAFS.

The influence of particle size distribution and alkali promoter effects on the linear-CO spectrum has not been recognized in most of the prior IR studies on nonacidic zeolite-supported metal catalysts. These factors should be taken into account when support effects in metal catalysts are studied using CO/IR spectroscopy. The spectral analysis method using deconvolution and curve fitting makes it possible now to determine the effect of the metal-support interaction on the electronic properties of the supported metal particles.

Acknowledgment. We thank Prof. Dr. J. H. van der Maas of the Department of Analytical Molecular Spectrometry at Utrecht University for helpful comments and the use of the FTIR instrumentation.

\section{Appendix. Correlation $v_{\mathrm{CO}}$ with Metal Coordination Number: Influence of Particle Size, Particle Morphology, and Particle Size Distribution}

The infrared band structure of $\mathrm{CO}$ adsorbed on Pt clusters supported on silica or alumina can be relatively sharp even for samples for which TEM shows a distribution of cluster sizes. Likewise, the $\mathrm{CO}$ vibrational band of homogeneous molecular Pt carbonyl clusters is very narrow also when these clusters contain more than 10 atoms, which is on the average the number of atoms per metal particle for the Pt/K-LTL catalyst as discussed in the paper. The differences in spectral appearance of the CO spectra as compared with those obtained for $\mathrm{Pt} / \mathrm{K}$ LTL seems contradictive; both larger and smaller platinum clusters give rise to narrower $\mathrm{CO}$ absorption bands. An explanation will be given below.

The relationship between the structure of metal surfaces and infrared vibrational frequency of adsorbed $\mathrm{CO}$ has been studied

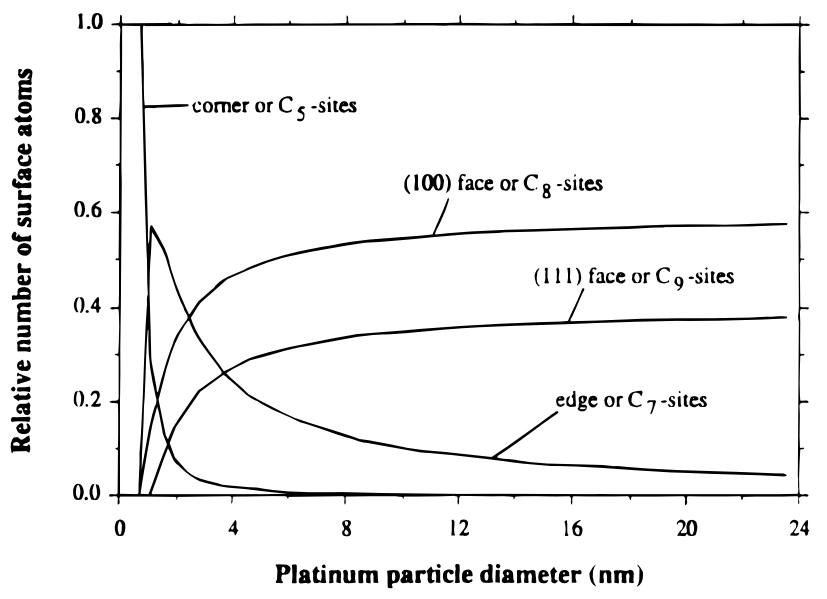

Figure 12. Variation of the relative number of surface atoms with metal particle size for a cuboctahedron. ${ }^{81}$

both theoretically ${ }^{73}$ and experimentally on supported metal particles $^{2,7,41-46}$ as well as on single-crystal surfaces. ${ }^{46-48}$ It was shown that the sharp linear-CO spectra for silica supported platinum particles can be explained in terms of the correlation between $v_{\mathrm{CO}}$ and the coordination number $\mathrm{CN}$ of the surface adsorption sites, the same correlation used here to interpret the CO spectra for Pt/K-LTL. The difference between CO spectra from silica and K-LTL supported platinum is mainly due to the large difference in average particle size. The equilibrium shape for (sufficiently large) fcc metal particles is an octahedron with (111) faces, more or less truncated by a cube having (100) faces and centered on the octahedron. The extent of truncation depends on the relative surface energies of the low-index faces. Van Hardeveld and Hartog 42 have published the results of many calculations describing these arrangements. The variation of relative number of surface atoms with metal particle size for a cuboctahedron is given below in Figure 12. Although the total number of surface atoms increases with increasing particle size, the relative contribution of the different types of surface atoms is changing. The most dramatic changes in the arrangement of the surface atoms occurs for particles smaller than $40 \AA$. Below this size the surface sites with low coordination numbers become relatively large. Thus, the metal particles on silica or alumina, which are larger than the zeolite supported clusters, are believed to expose low-index $\{(111)$ and (100)\} face atoms with corresponding high $v_{\mathrm{CO}}$ frequencies. Even in the case of a broad particle size distribution the surface structure of the catalyst will remain homogeneous, giving rise to sharp linear-CO bands in the IR spectrum. Only when the platinum particles become as small as $16 \AA$ the low-frequency CO absorption associated with edge and corner atoms (low $\mathrm{CN}$ ) become apparent as was shown for the EuroPt-1 Pt/SiO${ }_{2}$ catalyst. ${ }^{27}$

Also in the case of homogeneous molecular Pt carbonyl clusters such as Longoni-Chini oligomers, ${ }^{80}\left[\mathrm{Pt}_{3}(\mathrm{CO})_{6}\right]_{n}{ }^{2-}$, the same correlation between $v_{\mathrm{CO}}$ and metal coordination number $\mathrm{CN}$ can be used for interpreting the carbonyl stretching region of the corresponding infrared spectra. Although the clusters can contain up to 18 platinum atoms due to the regular kitelike structure, the coordination numbers of the metal atoms can only have the values $\mathrm{CN}=2$ for $n=1$ or $\mathrm{CN}=3$ and 4 for $n=2$, $3,4,5$, and 6 . The spectra published by Longoni and Chini for the polyanions in THF solution all show sharp linear-CO peaks with half-bandwidths of $c a .25 \mathrm{~cm}^{-1}$, which have almost identical patterns of two or three overlapping components. ${ }^{80}$ Therefore, the carbonyl bands in the spectra of $\left[\mathrm{Pt}_{3}\left(\mathrm{CO}_{6}\right]_{n}{ }^{2-}\right.$ (with $n=1-6$ ) may be attributed to $\mathrm{CO}$ molecules coordinated to $\mathrm{Pt}$ atoms with limited number of neighboring metal atoms $(\mathrm{CN}=2,3$, or 4$)$. Thus, the difference of the cluster 
morphology of Longoni-Chini oligomers and LTL-supported Pt clusters is believed to be the reason for the dissimilarity in the shape of the linear-CO IR spectra.

\section{References and Notes}

(1) Bernard, J. R. In Proceedings of the 5th International Conference on Zeolites; Rees, L. V. C., Ed.; Heyden: London, 1980; p 686.

(2) Hughes, T. R.; Buss, W. C.; Tamm, P. W.; Jacobson, R. L. Stud. Surf. Sci. Catal. 1986, 28, 725.

(3) Tamm, P. W.; Mohr, D. H.; Wilson, C. R. Stud. Surf. Sci. Catal. 1988, 38, 335 .

(4) Derouane, E. G.; Vanderveken, D. J. Appl. Catal. 1988, 45, L15.

(5) Tauster, S. J.; Steger, J. J. J. Catal. 1990, 125, 387. 219.

6) Han, W. J.; Kooh, A. B.; Hicks, R. F. Catal. Lett. 1993, 18, 209 ,

(7) Larsen, G.; Haller, G. L. Catal. Today 1992, 15, 431.

(8) Larsen, G.; Haller, G. L. Catal. Lett. 1989, 3, 103.

(9) Lane, G. S.; Modica, F. S.; Miller, J. T. J. Catal. 1991, 129, 145.

(10) Vaarkamp, M.; Van Grondelle, J.; Miller, J. T.; Sajkowski, D. J.; Modica, F. S.; Lane, G. S.; Gates, B. C.; Koningsberger, D. C. Catal. Lett. $1990,6,369$.

(11) Miller, J. T.; Meyers, B. L.; Modica, F. S.; Lane, G. S.; Vaarkamp, M.; Koningsberger, D. C. J. Catal. 1993, 143, 395.

(12) Vaarkamp, M.; Miller, J. T.; Modica, F. S.; Lane, G. S.; Koningsberger, D. C. In Proc. 10th Int. Cong. on Catal., Budapest, Hungary, 1992.

(13) Vaarkamp, M.; Miller, J. T.; Modica, F. S.; Koningsberger, D. C. $J$. Catal., in press.

(14) Vaarkamp, M.; Van Grondelle, J.; Van Santen, R. A.; Miller, J. T.; Modica, F. S.; Lane, G. S.; Koningsberger, D. C. In Proc. 9th Int. Zeolite Conf., Montreal, 1992.

(15) Vaarkamp, M.; Miller, J. T.; Modica, F. S.; Lane, G. S.; Koningsberger, D. C. J. Catal. 1992, 138, 675.

(16) McVicker, G. B.; Kao, J. L.; Ziemiak, J. J.; Gates, W. E.; Robbins, J. L.; Treacy, M. M. J.; Rice, S. B.; Vanderspurt, T. H.; Cross, V. R.; Ghosh, A. K. J. Catal. 1993, 139, 48.

(17) Modica, F. S.; Miller, J. T.; Meyers, B. L.; Koningsberger, D. C. in Proc. ACS Meeting, Chicago, 1993.

(18) Alvarez, W. E.; Resasco, D. E. Catal. Lett. 1991, 8, 53.

(19) Hong, S. B.; Mielczarski, E.; Davis, M. E. J. Catal. 1992, 134, 349.

(20) Mielczarski, E.; Hong, S. B.; Davis, R. J.; Davis, M. E. J. Catal. 1992, 134, 359.

(21) Besoukhanova, C.; Guidot, J.; Barthomeuf, D.; Breysse, M.; Bernard, J. J. Chem. Soc., Faraday Trans. 1 1981, 77, 1595.

(22) De Mallmann, A.; Barthomeuf, D. Stud. Surf. Sci. Catal. 1986, 28,725 .

(23) Larsen, G.; Haller, G. L. Catal. Sci. Technol. 1991, 1, 135.

(24) Han, W. J.; Kooh, A. B.; Hicks, R. F. Catal. Lett. 1993, 18, 193.

(25) Kappers, M. J.; Vaarkamp, M.; Miller, J. T.; Modica, F. S.; Barr, M. K.; Van der Maas, J. H.; Koningsberger, D. C. Catal. Lett. 1993, 21, 235.

(26) Lane, G. S.; Miller, J. T.; Modica, F. S.; Barr, M. K. J. Catal. 1993, 141,465 .

(27) Kappers, M. J.; Van der Maas, J. H. Catal. Lett. 1991, 10, 365. 9,121 .

(28) Kustov, L. M.; Ostgard, D. J.; Sachtler, W. M. H. Catal. Lett. 1991,

(29) Ostgard, D. J.; Kustov, L. M.; Poeppelmeier, K. R.; Sachtler, W. M. H. J. Catal. 1992, 133, 342.

(30) Eischens, R. D.; Francis, S. A.; Pliskin, W. A. J. Phys. Chem. 1956, $60,194$.

(31) Peri, J. B. J. Catal. 1978, 52, 144

(32) Rothchild, W. G.; Yoa, H. C. J. Phys. Chem. 1981, 74, 4186.

(33) Stoop, F.; Toolenaar, J. C. M.; Ponec, V. J. Catal. 1982, 73, 50.

(34) Primet, M. J. Catal. 1984, 88, 273.

(35) Haaland, D. M. Surf. Sci. 1987, 185, 1.

(36) Barth, R.; Ramachandran, A. J. Catal. 1990, 125, 467.

(37) Bartok, M.; Sarkany, J.; Sitkei, A. J. Catal. 1981, 72, 236.

(38) Sarkany, J.; Bartok, M. J. Catal. 1985, 92, 388.

(39) Boujana, S.; Demri, D.; Cressely, J.; Kiennemann, A.; Hindermann,

J. P. Catal. Lett 1990, 7, 359

(40) Jackson, S. D.; Glanville, B. M.; Willis, J.; McLellan, G. D.; Webb, G.; Moyes, R. B.; Simpson, S.; Wells, P. B.; Whyman, R. J. Catal. 1993, 139, 207.
(41) Sheppard, N.; Nguyen, T. T. In Advances in Infrared and Raman Spectroscopy; Clark, R. G. H., Hester, R. E., Eds.; Heyden: London, 1978; Vol. 5, p 67.

(42) Van Hardeveld, R.; Hartog, F. Adv. Catal. 1972, 22, 75; Surf. Sci. 1969, 15, 189.

(43) Della Betta, R. A. J. Phys. Chem. 1975, 79, 2519.

(44) Solomennikov, A. A.; Lokhov, Y. A.; Davidov, A. A.; Ryndin, Y. A. Kinet. Katal. 1979, 20, 714

(45) Toolenaar, F. J. C. M.; Bastein, A. G. T. M.; Ponec, V. J. Catal. 1983, 82,35 .

(46) Greenler, R. G.; Burch, K. D.; Kretzschmar, K.; Klauser, R.; Bradshaw, A. M.; Hayden, B. E. Surf. Sci. 1985, 152/153, 338.

(47) Brandt, R. K.; Hughes, M. R.; Bourget, L. P.; Truszkowska, K.; Greenler, R. G. Surf. Sci. 1993, 286, 15. 605 .

(48) Brandt, R. K.; Sorbello, R. S.; Greenler, R. G. Surf. Sci. 1992, 271 ,

(49) Kauppinen, J. K.; Moffatt, D. J.; Mantsch, H. H.; Cameron, D. G. Appl. Spectrosc. 1981, 35, 271; Anal. Chem. 1981, 53, 1454.

(50) Kauppinen, J. K.; Moffatt, D. J.; Cameron, D. G.; Mantsch, H. H. Appl. Opt. 1981, 20, 1866.

(51) Kauppinen, J. K.; Moffatt, D. J.; Holberg, M. R.; Mantsch, H. H. Appl. Spectrosc. 1991, 45, 411.

(52) Compton, D. A. C.; Maddams, W. F. Appl. Spectrosc. 1986, 40, 239.

(53) James, D. I.; Maddams, W. F.; Tooke, P. B. Appl. Spectrosc. 1987, $41,1362$.

(54) Yang, W. J.; Griffiths, P. R.; Byler, D. M.; Susi, H. Appl. Spectrosc. $\mathbf{1 9 8 5}, 39,282$

(55) Pierce, J. A.; Jackson, R. S.; Van Every, K. W.; Griffiths, P. R.; Hongin, G. Anal. Chem. 1990, 62, 477.

(56) Griffiths, P. R.; Wang, S. H. In Fourier Transform Infrared Characterization of Polymers; Ishida, H., Ed.; Plenum Press: New York, 1987; p 231.

(57) Griffiths, P. R.; Pierce, J. A.; Hongjin, G. In Computer-enhanced Analytical Spectroscopys; Meuzelaar, H. L. C., Isenhour, T. L., Eds.; Plenum Press: New York, 1989; Chapter 2.

(58) Friesen, W. I.; Michaelian, K. H. Appl. Spectrosc. 1991, 45, 50.

(59) Michaelian, K. H.; Friensen, W. I.; Yariv, S.; Nasser, A. Can. J. Chem. 1991, 69, 1786.

(60) Vandeginste, B. G. M.; De Galan, L. Anal. Chem. 1975, 47, 2124.

(61) Maddams, W. F. Appl. Spectrosc. 1980, 34, 245.

(62) The Mattson DECON program only allowed the fraction Lorentzian of the line shape function to be varied between $100 \%$ and $10 \%$. Thus, the "Gaussian" function mentioned with respect to the FSD routine has still $10 \%$ Lorentzian character $(\alpha=0.1)$.

(63) Levenberg, K. Q. Appl. Math. 1944, 2, 164.

(64) Marquardt, D. W. J. Soc. Ind. Appl. Math. 1963, 11, 431.

(65) Breck, D. W. Zeolite Molecular Sieves; Wiley: New York, 1974; p 114.

(66) Sachtler, W. M. H.; Ichikawa, M. J. Phys. Chem. 1986, 90, 4752.

(67) Angevaare, P. A. J. M.; Hendrickx, H. A. C. M.; Ponec, V. J. Catal.

1988, $110,11,18$

(68) Pitchon, V.; Primet, M.; Praliaud, H. Appl. Catal. 1990, 62, 317.

(69) Holloway, S.; Nørskov, J. K.; Lang, N. D. J. Chem. Soc., Faraday

Trans. 1 1987, 83, 1935 (Faraday Symp. 21).

(70) Ruett-R-Robey, J. E.; Doren, D. J.; Chabal, Y. J.; Christman, S. B. Phys. Rev. Lett. 1988, 61, 2779.

(71) Gadzuk, J. W.; Luntz, A. C. Surf. Sci. 1984, 144, 429.

(72) Hoffmann, F. M. Surf. Sci. Rep. 1983, 3, 107.

(73) Van Santen, R. A. J. Chem. Soc., Faraday Trans. 1 1987, 83, 1915

(74) Desjonqueres, M. C.; Cyrot-Lackman, F. J. Chem. Phys. 1976, 64, 3707.

(75) Saillard, J.-Y.; Hoffmann, R. J. Am. Chem. Soc. 1984, 106, 2006. (76) Cyrot-Lackmann, F. Adv. Phys. 1967, 16, 393; J. Phys. Chem. Solids 1968, $29,1235$.

(77) Gordon, M. B.; Cyrot-Lackmann, F.; Desjonquères, M. C. Surf. Sci. 1977, 68, 359. Desjonquères, M. C.; Cyrot-Lackmann, F. J. Chem. Phys. 1976, 64, 3707.

(78) Citrin, P. H.; Wertheim, G. K. Phys. Rev. B 1983, 27, 3176

(79) Blyholder, G. J. Phys. Chem. 1964, 68, 2772.

(80) Longoni, G.; Chini, P. J. Am. Chem. Soc. 1976, 98, 7225

(81) Kappers, M. J. Ph.D. Dissertation, Utrecht University, Utrecht, The Netherlands, 1993.

JP952503A 